\title{
The Distinguished Teacher Workshop Mode of Professional Learning Communities in Guangxi
}

\author{
YANG Maoqing | ORCID : 0000-0003-0996-5557 \\ Faculty of Education, Guangxi Normal University, Guilin, China - \\ Corresponding author \\ clove516@163.com \\ DENG Xiaoli | ORCID : 0000-0003-0153-3127 \\ Faculty of Education, East China Normal University, Shanghai, China \\ xiaoli589@yeah.net \\ LIUTian | ORCID : 0000-0002-1686-5186 \\ Faculty of Education, Western University, London, Canada \\ tliu455@uwo.ca
}

\begin{abstract}
Distinguished Teacher Workshops are important ways for teacher professional development. Through questionnaires and interviews with over 1,0oo participants, this paper reports the implementation of the Distinguished Teacher Workshops in Guangxi, China, covering their operational mechanism and initial outcomes: The empowerment of members; the strengthened internal motive of the community; and the enhanced vitality of professional development and a more sustainable development community for teachers. It is concluded that the Distinguished Teacher Workshops have shown that distinguished teachers play a leading role in teacher development in Guangxi.
\end{abstract}

\section{Keywords}

distinguished teacher workshop - professional development - workshop mode China 
With heightened global education reform, many countries have recognized the important role of teachers in education reform. Since 1966 when the International Labor Organization (ILO) and the United Nations Educational, Scientific and Cultural Organization (UNESCO) proposed the "proposal on the status of teachers", improving professionalism has become the goal of teacher education reform in many countries. China's Guidelines of the Mid-and Long-Term Plan for Educational Reform and Development 2010-2020 expects that "heightened teacher qualifications, improved teacher quality for a highly qualified teaching force with decent morality, sufficient professionalism, reasonable structure and full of vitality" (The State Council, 2010, May 5). It is recognized that the progress and prosperity of a country cannot be realized without education, while educational development relies on teachers. Therefore, teacher professional development is key to educational development and national revival.

\section{The Operation Mechanism of Distinguished Teacher Workshops in Guangxi}

The Distinguished Teacher Workshops in Guangxi are learning communities that are normally hosted each by a Distinguished Teacher and joined by several teachers at different levels, featured with "Learning Together, Guiding Teaching, Inspiring Research" in a certain area. Every workshop consists of moderators, mentors, participants and helpers with about 10 people who are chosen by the host distinguished teacher of the workshop. The aim is to introduce and expand the impactful role of distinguished teachers in an organized manner, and to nurture teachers to become leaders in a certain direction or a certain area of education in Guangxi.

1 This article is partly supported by the following funds: China's National Social Science Fund "Twelfth Five-Year Plan" 2014 Annual General Education Project "Study on the Reasonable Mobility Mechanism of Teachers in the Compulsory Education Stage in the New Urbanization Process in Ethnic Areas" (No. BMA140037). Research Center of Vietnam Research Center of Guangxi Normal University "Research on the Professional Development Support System of Rural Teachers in Vietnam" (No. YN2017005). Designated Funds for Bagui Scholars in Research on Education \& Development in Regions of Ethnic Minority, Guangxi Zhuang Autonomous Region of China, and grants from National. Thousands of young and middle-aged teachers in Guangxi higher education institutions funded projects. 
The learning mode of Guangxi Distinguished Teacher Workshops is "Team Learning", which aims to meet the needs of practical problem-solving, improve organizational efficiency and exert organizational benefits, collective wisdom and overall strength. The mode of activities is rooted in the notion of teachers as reflective researchers based on action research (Li, 2016; Stenhouse, 1983). Embracing an epistemology of "learning by doing", teachers gradually transform from professionals to reflective actors. The notion of teachers as reflective researchers fundamentally changes teacher professionalism regarding how they may apply their values, perspectives and skills in teaching practices. In Guangxi Teacher Workshop specifically, they form their research communities through the support of external experts, and the communities can guide teachers constantly to reflect on and adjust their educational practices.

\section{The Implementation Outcomes}

\subsection{Focusing on "Individual Differences": Empowering Participants and Motivating the Community}

The regular activities of the workshop community include observation classes, seminars of teaching and learning, classroom/school visits, and so on. Among them seminars of teaching and learning is the most routine activity. Such a community is a flat group in which there is no leader in absolute sense, but more is the case that every may serve as an organizer and participant with certain autonomy and power. The host distinguished teacher in the community empowers junior teachers with some administrative and professional rights, guarantees participants' voices of the community, and solidifies the collective ownership of the community.

\section{$3 \cdot 2$ \\ Pursuing of "Harmony with Diversity": Attaching Importance to the Construction of Membership to Enhance the Dynamism of the Workshop}

In the community of Distinguished Teacher Workshops, novice teachers can learn ways of practical thinking from distinguished teachers. Through communications and collaborations with different members, participants can learn collective wisdom in the sharing process of experiences and resources. By proactively participating in practical activities in these workshops, novice teachers can learn experiences from others, develop practical skillsets and promote professional development through reflections. The collective wisdom and social structure of the entire workshop have been transmitted from the first generation to the next one, from experienced to less-experienced, and 
members have achieved their construction of membership while gaining the professional development.

\subsection{Breaking through "the Limitation of Time and Space": Forming Stable Professional Development Communities and Expanding Practical Applications}

Time and space are necessary conditions for the success of the workshop development. Primary and secondary school teachers are generally under great teaching pressures, and it is difficult for them to have extra time and energy participating in teacher professional development communities. Therefore, school leaders supported teachers to plan a schedule which allows them to enjoy the workshop communities. During the workshop period, teachers devote themselves to the planned teaching and research activities demanded by the Distinguished Teacher Workshops. Meanwhile, the exclusive website of each workshop records and shares information conducive to the sustainability and development of the workshops. Online communities of teacher professional development eliminate time and space constraints on teachers' mutual exchanges and learning, as they can communicate with multiple participants at the same time. Also, e-learning activities minimize the tension in members of the community over time and space, as they make communications and learning more relaxed in the process. The Distinguished Teacher Workshops accomplished the networking of schools, especially those that are separated in urban and rural areas, and effectively solved the dilemma of work or study for teachers. It is also regarded as a strong benefit in the practical value of the online teacher professional development community.

The Radiation Impact of Distinguished Teacher Workshops in Guangxi

\subsection{Promoting Positive Interactions of "Teacher-Class-Student":}

Showcasing the Leading Role of Distinguished Teachers

Distinguished Teacher Workshops have enabled positive interactions between teachers and students via classes and become an effective way of teacher professional development. They reminded teachers of focusing on students by better understanding them, which also enabled junior teachers to be clear about their professional development through these workshops, to be effectively guided for better teaching practice. In the interactions of "teacher-classstudent", the new dynamism has been obtained through student feedback to teachers, which speeded up the growing process of junior teachers. Through 
the impact, influence, demonstration, guidance and other mechanisms, the workshops have become a autonomous developmental base for teacher professionalization in order to continuously expand the incubating function of these workshops, and realize the comprehensive development of teachers, students and schools in the long run. With the mechanism of the Distinguished Teacher Workshops, teachers have developed new, effective ways of professional development by focusing on students.

\subsection{Improving the Quality and Quantity of Teacher Development: Educating Key Excellent Teachers}

The Distinguished Teacher Workshops in Guangxi have enacted high-performing teachers with the capacity to overcome developmental challenges and achieve professionalism. After six years of tryouts, the Distinguished Teacher Workshops have spread across 14 cities, covering different classes and subjects at various levels of both basic and vocational education. In the way of "Led of Juniors by Seniors" in the workshops, the communities have been participated by nearly 4,500 key teachers, published more than 1,000 research papers on teaching reform, and collaborated on more than 600 research projects at different levels. With the principle of leading a group of individuals, rejuvenating a number of schools, and growing a region of education, the Distinguished Teacher Workshops carried the mission of the social responsibility, fulfilled the potential of precise poverty alleviation through education, and promoted the stable improvement of school quality in minority regions.

\section{References}

Li, J. (2016). Quest for World-Class Teacher Education? A Multiperspectival Study on the Chinese Model of Policy Implementation. Springer.

Stenhouse, L. (1983). The Relevance of Practice to Theory. Theory into Practice, 22(3), 211-215.

The State Council. (2010, May 5). Guojia zhongchangqi jiaoyu gaige he fazhan guihua gangyao 2010-2020. [The Guidelines of the Mid-and Long-Term Plan for Educational Reform and Development 2010-2020]. http://www.gov.cn/jrzg/2010-07/29/ content_1667143.htm. 